\title{
Equitable rationing of highly specialised health care services for children: a perspective from South Africa
}

Willem A Landman and Lesley D Henley East Carolina University, Greenville, North Carolina, USA, and Red Cross War Memorial Children's Hospital, Cape Town, South Africa, respectively

\begin{abstract}
The principles of equality and equity, respectively in the Bill of Rights and the white paper on health, provide the moral and legal foundations for future health care for children in South Africa. However, given extreme health care need and scarce resources, the government faces formidable obstacles if it hopes to achieve a just allocation of public health care resources, especially among children in need of highly specialised health care. In this regard, there is a dearth of moral analysis which is practically useful in the South African situation. We offer a set of moral considerations to guide the macro-allocation of highly specialised public health care services among South Africa's children. We also mention moral considerations which should inform micro-allocation.
\end{abstract}

(Fournal of Medical Ethics 1999;25:224-229)

Keywords: Children; health care priority setting; justice in health care; macro-allocation; micro-allocation; rationing; South Africa

In South Africa, the focus of public medicine has shifted to provision of primary health care services, leaving the funding of highly specialised health care in a state of uncertainty. How should the South African government discharge its constitutional and moral obligations in respect of advanced public medical care for children?

\section{Moral and legal commitments}

In its white paper, the Department of Health provides the moral underpinnings of future health care for children. In addition to equity, defined as " $(T)$ he universal provision of services on the basis of need rather than any other criterion", ${ }^{1}$ the government believes the "...moral and ethical basis for the provision of MCWH (maternal, child and women's health)" should be in keeping with internationally agreed upon principles in the United Nations Convention on the Rights of the Child. ${ }^{2}$ Services must also be “... efficient, cost-effective and of a good quality". 3
Correspondingly, the Bill of Rights in the conis stitution entitles every child under 18 to basic nutrition, shelter, basic health care services an social services. ${ }^{4}$ The government has yet to defin है "basic health care services" to which each child is legally (and morally) entitled. "Basic health care services" could, for example, refer only to a fixe $\phi$ package of primary health care services ${ }^{5}$ available. for all children, or it could also include healt care for children with special needs which may be relatively rare and costly to treat but are nevertheless basic in the sense of being necessar for survival and adequate functioning. Such carê tailored to the needs of identified specialties could be viewed as essential highly specialised care, or the tertiary equivalent of essentia primary health care. The scope of the definition of "basic health care services" will have crucia implications for children with special needs్ Children's socio-economic rights enjoy special protection in the constitution since they are cons sidered "clear, near-absolute core entitlements' which could receive priority were the judiciar called upon to allocate economic resources to guarantee these rights.

In practice, the government has taken steps to. improve children's health care. For example, the introduction of free health care for all children under six and pregnant women, ${ }^{8}$ improved vaccio nation coverage and extensive clinic-upgrading programmes should lead to considerable reduç tions in morbidity and mortality from acute, gen⿳亠口冋 erally preventable, diseases. In turn, the govern? ment is proposing that unique and highly specialised health care services for children wit complex conditions be limited to ten centrallo funded hospitals which will be considered na@ tional resources. Access to these services will be on the basis of "need and non-discrimination"s and, to this end, the white paper singles out "... the poorest patients" and "... those outside the imme. diate geographical location of the facilities". ${ }^{9} \stackrel{?}{?}$ 
Agreement on definitions of highly specialised health care services, and a formula for their funding, is being negotiated between the national and regional departments of health. These services are likely to include the following characteristics: low patient volume, high cost per patient, significant economies of scale, better results with large units, and requiring a complex team of people to provide long term follow-up care (Department of Health, unpublished communication, 1996). Clearly, it will not be possible to provide these services to everyone who might benefit from them, making rationing inevitable.

Against this background of extreme health care need, scarce resources, and a commitment to seemingly conflicting moral demands of equal constitutional rights, equity, efficiency, costeffectiveness and quality, how might the government achieve a just allocation of public health care resources for children? We offer a set of moral considerations that, if acted upon, would bring these commitments together coherently and give practical expression to the constitutional right of children to highly specialised health care services and to the government's commitment to equity. The considerations we propose are not the outcome of a philosophical thought-experiment about what rational choosers might decide behind a veil of ignorance in some original position, ${ }^{10}$ even though such intellectual exercises yield important normative insights. Instead, the framework for our discussion is set by the factual egalitarian commitments in the Bill of Rights and the white paper on health, and the realities of great need and scarcity.

We confine ourselves to provision of highly specialised health care services, examples of which might include organ transplantation, high technology neonatal care, and treatment of childhood cancers, cystic fibrosis (CF), and chronic renal failure. We assume there is a dedicated health care budget for children, a portion of which will be set aside for highly specialised services even though resources are at present being directed away from tertiary care. We further assume public policy seeks to give content to children's constitutional right to "basic health care services" by setting and implementing priorities for a social minimum which goes beyond essential primary health care. We believe ours is a more rational approach to distribution than the status quo rationing by default, which is uneven and reflects arbitrary historical and policy choices. Although our main focus is macro-allocation, we mention moral considerations that should inform micro-allocation.

\section{Macro-allocation}

\section{Prevention}

The current, public policy emphasis on an essential primary health care package is the first rational step towards achieving equity (as defined), or, in a wider sense, equality of basic opportunities. It is a policy that expresses a basic moral commitment to primary prevention, amounting to a form of triage $^{11}$ (a system of priority treatment to maximise the survival rate) on a national scale in the prevailing socio-economic conditions, and given that everything cannot be done at once.

Essential primary health care, which includes maternal and child health services, offers the most cost-efficient way of reducing much of the disease burden among children without drastically increasing public expenditure, ${ }^{12}$ which, in turn, safeguards children's basic opportunities to develop their potential. Apart from costs incurred, and initially these may be high, there would be costs avoided, such as the future cost of treating untreated disease and disability, as well as lost productivity over the long term. ${ }^{13} 14$

\section{NON-ABANDONMENT}

Since not all disease is amenable to prevention and acute management, on what rational basis could one set priorities beyond primary health care? Conversely, how do we value equally the lives of children with acute, preventable conditions and those with complex or long term, possibly incurable, conditions? ${ }^{15}$

We propose a basic moral and public policy commitment to non-abandonment. As far as possible, no identified area of vital health care need should be excluded. Health is a basic need and highly specialised health care is an intermediate need necessary for meeting that basic need. ${ }^{16}$ In terms of such a commitment, on a macro level every child would have an equal chance to get the health care services necessary to develop his or her potential.

Non-abandonment takes seriously one of the basic elements of a just health care system, namely, fair distribution of the burdens of rationing. ${ }^{17}{ }^{18}$ As tertiary health care services are cut, those with conditions that are expensive and complex to treat carry an excessive burden. Without highly specialised health care services in the public sector, these children will be denied access to life-preserving and life-enhancing health care as ability to pay becomes the sole criterion for receiving health care only available in the private sector. Since this would systematically disadvantage the poorest children with special needs, it would be a further breach of government policy. 
In addition to these underlying reasons of egalitarian justice (relating to equal individual rights, equity, and fairness), there are good utilitarian reasons for a commitment to non-abandonment of highly specialised health care. It would promote or benefit other elements of a just health care system, such as effective health care education and training, and the pursuit of high quality biomedical research. ${ }^{18}$ As experience is gained in treating expensive diseases and conditions, cost may well be reduced, and much might be learned in the process. $^{19}$

\section{Rationing formula}

We propose the following, rationing or prioritysetting formula which might achieve nonabandonment of highly specialised health care on a macro level in a way that maintains a balance between the different areas of vital health care need and their distribution in the population. ${ }^{20}$ Ascertain the number of children in an identified area of highly specialised health care, for example $\mathrm{CF}$, and multiply it by a unit cost (the cost of standard medical treatment per child per year) to determine the overall cost of treating children with $\mathrm{CF}$ per year. Having done the same for other areas of highly specialised health care, sum the costs for all identified areas of care, express the total available health care budget for highly specialised health care for children for a particular year as a percentage of that sum, and fund each specialty according to that percentage. In these circumstances non-abandonment serves the end of egalitarian justice by making provision for numbers in a specific area of highly specialised health care need in proportion to the incidence and prevalence of that need among the population.

For various reasons, the methods of calculating the cost of treatment would vary from one condition to another. We use a biomedical, specialtybased model to estimate need as it most accurately reflects de facto practice, although other approaches to estimation of need are possible. ${ }^{21}$ However, without accurate national data on the extent of met and unmet need for highly specialised health care services, reliance on international incidence and prevalence rates would be unavoidable in the short term.

Assume, for argument's sake, that only $55 \%$ of overall required funding is available. Each area of highly specialised health care would receive $55 \%$ of funds needed. These funds would be channelled to the ten central hospitals offering highly specialised health care, with allowances for uneven geographical spread of patients within specialties. Shortfalls will have to be accommodated on an institution-based specialty or micro level. However, these could be reduced in different ways by macro-level measures, such as? reapportionment of the national budget to in $\overrightarrow{\vec{\omega}}$ crease the overall health care budget for children or using some of the funds generated by the intro $\frac{5}{5}$ duction of a national lottery.

The Department of Health's commitment tō good quality care requires that funds made avail able to specialties in central hospitals be used for treatment that meets universal standards of highly specialised medical care. Such a commitmen would preclude stretching resources to accommos date more than the number budgeted for on macro level on the basis of non-abandonment and funding according to the proposed formula. $\quad \stackrel{\omega}{\omega}$

Would a policy based on non-abandonmeniv result in the best economic use of resources? In South Africa, equality is a constitutionally man을 dated ideal, the realisation of which might require using health care resources in ways that delive less rather than more benefit. Equality requires that some resources be used to combat even theo most severe and costly disease and disability soe that every child has some chance to develop his of her potential, and this means sub-optimal use of resources in terms of maximising overall beneficiaf outcome. This illustrates the fundamental normaon tive tension between two basic moral values tha underlie distributive choices, namely equality and wellbeing. ${ }^{22}$

\section{Cost-effectiveness considerations}

However, according to the government, children's health care services must be cost-effective and efficient. If this requires using scarce resources to confer the most overall benefit or well-being (fo: example, in the form of quantifiable extension o life or improvement of quality of life), on the greatest number, it will conflict with the govern? ment's own commitments to equity or justice as.

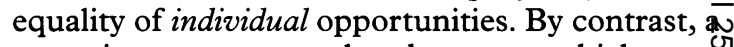
commitment to non-abandonment, which sup ports the equitable provision of highly specialisec health care, will preclude allocation of totaw resources in the most cost-effective way. In sucl? an approach, considerations of efficiency (define as "the attainment of the best outcome or result a the lowest possible cost"), ${ }^{23}$ would be limited to choices between different kinds of treatments fo 5 the same conditions within specialties, and would not underpin choices among services of specialties. ${ }^{24}$ Cost-effectiveness gains are possible through the use of marginally less effective, but very much cheaper, treatments, although sucho decisions may be controversial. ${ }^{25}$ At an institu tional level, cost-effectiveness should operates through the concentration of specialty services 
that develop tested, efficient treatment pathways and adopt sound managerial principles. ${ }^{26}$ Likewise, cost-effectiveness considerations require that highly specialised health care, for example, paediatric organ transplantation, be restricted to some, or only one, central hospital.

A policy based on non-abandonment requires the inclusion of most disease categories, regardless of cost. But is it not more rational to give priority to cheaper treatments that potentially provide small benefits to many children rather than focus on expensive treatments that potentially provide large benefits to a few children, for the same overall expense? Weighting cost against other morally relevant variables means that some health care services should be channelled towards individual high-cost/high-benefit treatments for small numbers of children. ${ }^{22}$ For some children with special needs, this might be the only way to promote equality of basic opportunities, given extreme scarcity.

An example of such a commitment to nonabandonment would be to regard some, nonexperimental, transplant surgery no differently from other forms of expensive therapy. Indeed, a thoughtful comparison of high treatment costs of paediatric heart transplantation, CF, childhood acute lymphoblastic leukaemia, and preterm care for infants could find no moral justification for arbitrarily excluding any particular treatment category, simply because it was too expensive. ${ }^{15}$ "Why," the authors ask, "... should a child with incurable heart disease be denied the chance of a healthy childhood granted to others with similarly devastating afflictions?", the cost of all being prohibitively high. ${ }^{27}$ Moreover, given good survival rates, heart, kidney and liver transplantation, in the South African context, may be cost-effective since it is cheaper to transplant these organs than to treat patients repeatedly for complications of chronic heart, kidney or liver disease. ${ }^{28}$ Treatment of a relatively small number of children with chronic diseases, although expensive, is justified when cost is weighted against other morally relevant considerations, such as equality of opportunity and non-discrimination, and individual benefit. ${ }^{22}$

\section{Medical futility}

A commitment to non-abandonment also requires treatment of severe disease and extreme disability. Severity of disease is not, however, an absolute moral consideration and, given scarcity and great need, other morally relevant variables, such as cost and beneficial outcome, must be balanced in the pursuit of equality of basic opportunities. ${ }^{22}$ Therefore, we would not support treatment, beyond comfort care, of a child whose clinical condition is so severe that no beneficial outcome whatsoever is likely. For example, aggressive treatment, beyond comfort care, of an anencephalic infant is futile by all generally accepted goals of medicine, such as caring, healing or saving life. Some might hold the extreme position that a goal of medicine is to preserve life at all cost, even physiological life with rudimentary or no consciousness. We reject this view. However, all judgments about medical futility are value-laden and should not be used as a method of rationing care. ${ }^{29}$ Even a judgment about medical futility that appeals to purely physiological outcomes is not value-neutral but contains embedded normative choices, for example, about the value of a life and the goals of medicine. ${ }^{30}$

In sum, we believe our commitment to non-abandonment is the best way to balance all morally relevant considerations in a situation of extreme health care need and resource scarcity. It accommodates the formidable tensions that exist between equality of basic opportunities and achieving the most beneficial overall outcome, as well as other tensions created by factors such as cost, and prevalence and severity of disease.

\section{Micro-allocation}

Once a procedure is in place, on a macro level, to prevent arbitrary exclusion of categories of highly specialised care, it seems rational to use available health care resources to generate the most possible good, and this suggests a moral commitment to maximise benefit or promote the most beneficial outcome.

If we assume $45 \%$ underfunding for all specialties, and if specialties are funded according to the proposed formula, then only $55 \%$ of identified need in a specialty can be treated. Health care professionals will have to decide which children will receive highly specialised care that cannot be provided to everyone who needs it. On what justifiable moral basis could such exclusion be done on a micro level, since the public system is designed precisely to assist those without the ability to pay, and since children present a special case and should not be judged in terms of standards such as previous contribution to society, effort, or prudent planning?

We propose, within specialties, children be selected, in the first instance, according to a "first come, first served" (queuing) rule. ${ }^{31}$ This kind of random selection aimed at addressing equity on a micro level, in respect of children with equal need for survival or adequate functioning, could be made fairer by adopting corrective measures sensitive to considerations such as access to care and 
geographical location. Does this mean that patients already receiving treatment have absolute priority over those who arrive later with more urgent needs or better chances of success? We believe not. For example, in a paediatric intensive care unit (PICU), there may be times when a child, with a more urgent need or a greater likelihood of benefit, might need to displace a child with a poor prognosis. Although admission to a PICU establishes a presumption in favour of continued treatment, requirements of medical utility sometimes justify early discharge to make room for others with more urgent need or higher probability of benefit. This does not constitute abandonment if alternative, more appropriate, care is provided. ${ }^{31}$

Queuing would provide a pool of potential patients who, depending on the nature of their condition, would need to meet a set of selection criteria $^{32}$ based on medical utility, defined as the maximisation of the welfare of patients in need of treatment. Where rationing is unavoidable, medical utility is justified because scarce resources should only be distributed to individual children with a reasonable chance of benefiting from them. Failure to do so would result in a waste of scarce resources. ${ }^{31}$ The development of explicit criteria would also be in line with a recent constitutional court ruling on access to life-prolonging resources. According to the judgment:

“. . .while each claimant seeking access to public medical resources is entitled to individualised consideration, the lack of principled criteria for regulating such access could be more open to challenge than the existence and application of such criteria". ${ }^{33}$

Where medical utility is roughly equal between children eligible for the same resource (for example, a donor heart), we propose queuing, randomisation or a lottery, whichever procedure is most appropriate and feasible under the circumstances. ${ }^{31}$ Here, where there are no obvious differences among patients in terms of medical need and likelihood of success, random selection is justified on grounds of equity and equal evaluation of lives.

On the micro level, because rationing decisions are value laden, determination of medical utility (including choice and weighting of patient selection criteria) will require constant medical and public scrutiny. Significantly, the government proposes periodic national health summits and the formation of hospital committees to encourage public participation in the planning and provision of health care services. ${ }^{34}$ However, democratic debate about normative question such as fair rationing procedures will likely create its own in-built tensions, as society is forced t $\overrightarrow{\overrightarrow{0}}$ make tragic choices between individual lives and the overall good, in other words to put a price of life. ${ }^{22}$ Still, such debate would form part of a honest, open and rational attempt to achieve equitable rationing or egalitarian justice consisto ent with the demands of a democratic constitus tion, and given the intractable combination of extreme need, scarce resources, and the inevitabi ity of rationing exclusions.

Does micro-allocation mean many childre needing highly specialised health care will bie abandoned after all? At least on a macro level, policy based on non-abandonment should givie every child an equal chance to get the health care necessary for developing basic opportunities, n\& one being discriminated against on account of factors beyond his or her control such as cost of treatment, or incidence or severity of disease Importantly, non-abandonment, as proposed, will make a material difference to where health care resources are channelled. Therefore, a distribu哩 tion policy premised on non-abandonment wi yield outcomes entirely different from other possible approaches. For example, a straightforo ward overall cost-benefit approach would likel\% result in the exclusion of whole categories of chiF dren with special needs (for instance, those needs ing organ transplantation) because resource could be used more cost-effectively on children elsewhere in the health care system. However, on a micro level, given extreme need and scarcits rationing exclusions (and therefore tragic choices] are inevitable. Still, we believe a policy based on non-abandonment is the fairest way to give concrete expression to the government's morad and legal commitment to greater equality an non-discrimination in the distribution of basi health care services among children.

\section{Conclusion}

The principles of equality and equity, respectivel in the Bill of Rights and the white paper on health provide the moral and legal foundations for future health care for children in South Africa. In reality extreme need and scarcity will seriously limit the government's ability to fulfil its commitment to equal health care rights for children, especiallo their equal right to highly specialised health care

To achieve equality of basic opportunities of the macro level, we propose a national health policy for children premised on the principles of prevention and non-abandonment. We argue the all effective highly specialised health care services for children should be accommodated in the 
health care system. Apart from an egalitarian justification, it could be argued that abandoning existing specialties would have adverse consequences throughout the health care system and that, once abandoned, they would be very costly to resurrect. We reject grounding the macroallocation of health care resources on purely costeffectiveness calculations because they are indifferent to equality of opportunity and equity. Indeed, attaining equality on the macro level, through non-abandonment, may require using resources that deliver less rather than more overall benefit. Non-abandonment also addresses the formidable tensions in health care resource allocation generated by considerations of equality and utility, treatment costs, and severity and prevalence of disease and disability. Whereas a policy grounded in cost-benefit and costeffectiveness principles would likely result in whole categories of highly specialised health care being excluded because better outcomes for children could be obtained elsewhere in the health care system, non-abandonment on a macro level would give most children with special needs an equal chance of realising their potential.

Given extreme need and scarcity, it would not be possible to provide highly specialised health care services to all children who might benefit from them, making rationing inevitable. To this end, we propose that within each specialty, children be selected on a "first come, first served" basis. Thereafter, to promote the best use of scarce resources with the least waste, children should meet selection criteria based on medical utility. Where medical need and probability of success are roughly equal among eligible children with similar conditions, equal evaluation of lives requires selection according to an appropriate form of random selection.

Willem A Landman, DPhil, is Professor in the Department of Medical Humanities, School of Medicine, East Carolina University, Greenville, North Carolina, USA. Lesley D Henley, PhD, is a Senior Lecturer in the Department of Paediatrics and Child Health, Institute of Child Health, Red Cross War Memorial Children's Hospital, Cape Town, South Africa.

\section{References}

1 Department of Health. White paper for the transformation of the health system in South Africa. Pretoria: Government Printer, 1997:224.

2 See reference 1:103.

3 See reference 1:98.

4 Constitution of the Republic of South Africa Act, No 108 of 1996

5 See reference 1:36-8.

6 De Vos P. Pious wishes or directly enforceable human rights? social and economic rights in South Africa's 1996 constitution. South African Fournal of Human Rights 1997;13:67-107.

7 See reference 6:88.

$8 \mathrm{McCoy} \mathrm{D}$. Free health care for pregnant women and children under six in South Africa: an impact assessment. Cape Town: Child Health Unit, University of Cape Town for the Health Systems Trust, 1996.

9 See reference 1:176-7.

10 Rawls J. A theory of justice. Oxford: Oxford University Press, 1972.

11 Beauchamp TL, Childress JF. Principles of biomedical ethics [4th ed]. New York, Oxford: Oxford University Press, 1994: 385.

12 World Bank. Development report: investing in health. Oxford: Oxford University Press, 1993.

13 Hussey GD, Lasser ML, Reekie WD. The costs and benefits of a vaccination programme for haemophilus influenzae type B disease. South African Medical fournal 1995;85:20-5.

14 Viljoen DL, Buccimaza S, Dunne T, Molteno C. The prevalence and prevention of neural defects in Cape Town. South African Medical Fournal 1995;85:630-2.

15 Hugo-Hamman CT, Vosloo SM, de Moor MMA, Odell JA. Paediatric heart transplants: should we do them? South African Medical fournal 1991;80:434-6.

16 Doyal L, Gough I. A theory of human need. London: Macmillan, 1991.

17 Buchanan AE. Privatization and just health care. Bioethics 1995;9:220-39.

18 Benatar SR. What makes a just healthcare system? British Medcial fournal 1996;313:1567-8.

19 Harris J. More and better justice. In: Bell M, Mendus S, eds. Philosophy and medical welfare. Cambridge: Cambridge University Press, 1988:75-96.

20 Doyal L. Needs, rights, and equity: moral quality in healthcare rationing. Quality in Health Care 1995;4:273-83.

21 McPherson M, Arango P, Fox $\mathrm{H}$ et al. A new definition of children with special health care needs. Pediatrics 1998;102:13740.

22 Landman WA, Henley LD. Tensions in setting health care priorities for South Africa's children. Fournal of Medical Ethics 1998;24:268-73.

23 See reference 1:224.

24 Klein R. Priorities and rationing: pragmatism or principles [editorial]. British Medical fournal 1995;311:761-2.

25 Lee C, Sabin C, Miners A. High cost, low volume care: the case of haemophilia. British Medical fournal 1997;315:662-3.

26 Marais AD, Benatar SR. Planning rational management of chronic diseases-lessons from a lipid clinic. South African Medical fournal 1995;85:340-1.

27 See reference 15:435.

$28 \mathrm{Kahn}$ D. Supraregional funding for transplantation [editorial] South African Medical fournal 1994;84:590-1.

29 Jecker NS. Futility and rationing. American fournal of Medicine 1992;92:189-96.

30 Halliday R. Medical futility and the social context. Fournal of Medical Ethics 1997;23:148-53.

31 See reference 11:378-86.

32 Kilner JF. Microallocation. In: Reich WT, ed. Encyclopedia of bioethics: vol 2 [rev ed]. New York: Macmillan, 1995:1075-84.

33 Soobramoney $v$ Minister of Health (Kwazulu-Natal) CCT 32/97 (27 November 1997).

34 See reference 1:33-6. 